\title{
PLAUTO E O TRIUNFO DA TRAGÉDIA
}

\author{
LiLiAn Nunes da CostA*
}

Universidade de Campinas

\begin{abstract}
Resumo. A presença de elementos variados da tragédia, da épica e mesmo da poesia lírica na comédia de Tito Mácio Plauto (c. 254-184 a.C.) tem sido reconhecida por estudiosos como, respectivamente, Christenson (2000), Oniga (1985) e Traill (2005). Contudo, tal mescla de gêneros poéticos presente no corpus da obra plautina está longe de representá-los em uma convivência pacífica. Ao contrário: em vários momentos a evocação de outros gêneros poéticos parece apontar para uma atmosfera de emulação entre o gênero cômico e aqueles. Nossas pesquisas vêm apontando para o predomínio de alusões à tragédia (ou intermediadas por ela). Mas, como gostaríamos de frisar, não se trata de uma mera questão de quantidade de referências: algumas vezes, essa disputa (e a hierarquia tradicional) é mesmo tematizada, como em Anfitrião, Os cativos, Truculento. Na presente exposição, procuraremos observar mais de perto, em passagens de Plauto, o suposto triunfo que a tragédia teria sobre a comédia, a fim de apurar em que medida isso é verificável em algumas de suas peças.
\end{abstract}

Palavras-chave. Plauto; comédia; tragédia; épica; lírica.

D.O.I. 10.11606/issn.2358-3150.v18i2p88-101

A obra do comediógrafo romano Tito Mácio Plauto (c. 254-184 a.C.) conta com peças que não se limitam exclusivamente ao contexto de seu próprio enredo, muitas vezes tratando, ainda que en passant, da conjuntura teatral de forma mais ampla. Nelas chegam a ser mencionados autores, ${ }_{1}^{1}$ atores, ${ }^{2}$

Doutora em Linguística/Estudos Clássicos pela Universidade de Campinas (2014), com estágio na Ruprecht-Karls Universität, Heidelberg, Alemanha. Nossa pesquisa contou com apoio do CNPq (processo n ${ }^{\circ} 140562 / 2010-9$ ).

"Artigo recebido em 25.set.2015 e aceito para publicação em 14.dez.2015.

${ }^{1}$ Uma célebre passagem da peça Mostelária (Mostellaria) cita os poetas gregos Dífilo e Filemão, que se dedicaram à Comédia Nova: "Si amicus Diphilo aut Philemoni es, / Dicito is quo pacto tuus te seruos ludificauerit. / Optumas frustrationes dederis in comoediis" ("Se você é amigo de Dífilo ou de Filemão, você dirá a eles de que maneira seu escravo enganou você. Você terá dado excelentes confusões para as comédias", Most. 1149-52). Para uma discussão sobre essa passagem (e menções dessa natureza) e a ilusão nas peças plautinas, cf. Cardoso 2010, 95-126.

${ }^{2}$ Em Báquides (Bacchides) encontra-se a seguinte brincadeira, em que se menciona o título de outra comédia plautina: "Etiam Epidicum, quam ego fabulam aeque ac me ipsum amo, / Nullam aeque inuitus specto, si agit Pellio" ("Mesmo Epídico, uma peça que eu amo como a mim mesmo com razão, com razão eu dela não gosto e a ela assisto de mau grado se o Pelião estiver atuando", Bacch. 214-5). 
espectadores, ${ }^{3}$ espaço físico ${ }^{4}$ e convenções performáticas. ${ }^{5}$ Encontram-se ainda, na obra plautina, referências aos gêneros teatrais: com frequência, não apenas a comédia é mencionada, mas também a tragédia, um gênero ao qual, pelo que se tem notícia, Plauto não se dedicou diretamente. Como aponta Isabella T. Cardoso (2005), muitos desses comentários "metateatrais"'6 não se encontram deslocados dentro das peças e, em alguns casos, são especialmente motivados pelo enredo. Nesta breve exposição, gostaríamos de rever de que forma isso ocorre, aprofundando a questão em relação às referências a gêneros poéticos diversos (tragédia, épica e lírica) em algumas comédias plautinas, como Anfitrião (Amphitruo) e Os cativos (Captiui).

Em Anfitrião, a peça que discorre de modo mais explícito e enfático sobre os gêneros trágico e cômico, o enredo se desenvolve em torno de um episódio mítico (o nascimento de Hércules). Temas mitológicos não são desenvolvidos centralmente, i.e. como enredo, nas demais comédias legadas de Plauto, as fabulae palliatae (nem, ao que se saiba, nas peças que lhe serviam de modelo, obras da Comédia Nova grega, a Néa). ${ }^{7}$ Entre as personagens de Anfitrião, encontram-se os deuses Júpiter e Mercúrio, que têm, excepcionalmente, papéis na ação da peça, ao contrário do que ocorre em outras comédias plautinas, em que divindades têm apenas a função de apresentar o prólogo. ${ }^{8}$ Há ainda outras personagens de estatuto elevado (estatuto que, segundo o prólogo de Anfitrião, seriam mais condizentes com uma tragédia), como o general Anfitrião e sua esposa, Alcmena. A presença dessas personagens "superiores" em cena, juntamente com um escravo (personagem de estatuto mais baixo), é, pois, precisamente o critério alegado pela personagem

${ }^{3}$ São várias as referências à plateia, a maioria em prólogos, como ocorre em Os cativos (Captiui): "Iam hoc tenetis? Optumest. / Negat hercle ille ultimus. Accedito" ("Vocês entenderam? Ótimo. Por Hércules, aquele ali na última fileira diz que não. Chegue mais perto", Capt. 10-11).

${ }^{4} \mathrm{Um}$ exemplo pode ser encontrado em Anfitrião (Amphitruo): "Vt conquistores singula in subsellia / Eant per totam caueam spectatoribus" ("Que inspetores passem de lugar em lugar por toda a plateia, fiscalizando os espectadores", Amph. 65-6).

${ }^{5}$ Como em Os cativos: "Nunc certa res est, eodem pacto ut comici serui solent, / Coniciam in collum pallium, primo ex med hanc rem ut audiat" ("Agora está decidido, do mesmo modo que costumam fazer os escravos de comédia, jogarei o pálio ao redor do pescoço, para que ouça primeiro de mim esse caso", Capt. 778-9).

${ }^{6}$ Consideramos, aqui, o termo "metateatral" como aquilo que, no teatro, se refere ao próprio teatro. Sobre "metatheatre", termo cunhado por Abel (1963), e seu uso nos estudos plautinos (Barchiesi 1969, Slater 1985), cf. Cardoso 2005, 21 ss.

${ }^{7}$ Os mitos estavam presentes, porém, em produções anteriores, da Comédia Antiga e Média gregas. Sobre isso, cf., por exemplo, Adriane S. Duarte (Aristófanes 2005, xv-xvi). Para alusões mitológicas em peças de Plauto, ver Zagagi 1980, 1986.

${ }^{8}$ É o caso das seguintes peças: Aululária (Aulularia), cujo prologuista é o deus Lar (Lar familiaris); Cásina (Casina), com a deusa Boa Fé (Fides); Cistelária (Cistellaria), que traz o deus Auxílio (Auxilium); O cabo (Rudens), que conta com Arturo (Arcturus). Sobre a presença de divindades em prólogos plautinos, cf. Abel 1955. 
divina Mercúrio, num prólogo repleto de considerações metateatrais, para que a peça seja denominada "tragicomédia" (tragicocomoedia, Amph. 59, 63). ${ }^{9}$

Em Os cativos, é também no prólogo que se comenta explicitamente sobre certas convenções cômicas e trágicas. O Prologus (que tende a ser identificado, por editores e demais estudiosos modernos, como o chefe da trupe), ao explicar o enredo, afirma que o velho Hegião tivera recentemente um filho feito prisioneiro, por ocasião da guerra entre a Etólia e Élis (Capt. 24-5). Tendo falado em peleja (belligerant, in bello; Capt. 24-5), o prologuista trata de esclarecer que os combates não seriam representados no palco, pois não seria adequado uma companhia cômica apresentar, de improviso, uma tragédia (Capt. 58-62). Ou seja, apresenta-se, na passagem em questão, a guerra como tópos típico da tragédia, não da comédia.

Interessante é observar que seis das oito ocorrências do termo tragoedia no corpus plautino se encontram nos prólogos das respectivas peças (Amph. 41, 51, 52, 54, 93; Capt. 62). ${ }^{10}$ Uma mescla de gêneros (ou "cruzamento de gêneros"), ${ }^{11}$ como sugerem os respectivos prólogos, está, pois, associada, a essas duas peças (mais explicitamente em Anfitrião que em Os cativos). Mais precisamente, em ambas ocorre, conforme já se apontou, ${ }^{12}$ uma espécie de negociação quanto ao gênero da peça a ser assistida.

As outras duas ocorrências da palavra tragoedia estão em Gorgulho (Curculio 591) e Pênulo (Poenulus 2), peças em que a discussão genérica se mostra, ao menos à primeira vista, menos abrangente. Encontram-se igualmente fora de contexto que se refira a cruzamento de gêneros os termos tragicus e tragoedus, que aparecem uma vez cada nos textos de Plauto legados, designando o ator de tragédias (Pers. 465; Poen. 581)..$^{13}$

De toda forma, essas referências não deixam de ser significativas a nossa apreciação: todos esses vocábulos relacionados ao gênero trágico evidenciam o quanto se faz presente a tragédia nas comédias de Plauto. No entanto, uma análise mais atenta revela que outros gêneros, nomeada-

\footnotetext{
${ }^{9}$ Uma análise mais completa sobre o trecho, bem como toda a obra Anfitrião, pode ser encontrada em Costa 2010.

${ }^{10}$ A enumeração das referências se baseia no Lexicon Plautinum de G. Lodge (1962) e em resultados obtidos com a ferramenta de busca da base de dados online Perseus Digital Library; para termos até a letra " $\mathrm{p}$ ", recorremos também ao Thesaurus linguae latinae (ThLL). Algumas das ocorrências, em Plauto, de termos relacionados a obras e poetas citados neste artigo foram elencadas por Knapp (1919a, 1919b).

${ }^{11}$ Adotamos a expressão ("Kreuzung der Gattungen") de W. Kroll (1924).

${ }^{12}$ Cf. discussão em M. Leigh (2004, 78-81).

${ }^{13}$ F. Leo, em sua edição do texto plautino (publicada primeiramente em 1896), infere tragicae sunt em Poen. 1168, opção não adotada por W. M. Lindsay (primeira edição em 1903), nem por A. Ernout (primeira edição em 1938), que preferem thraecae sunt, alternativa mais próxima da que se encontra no manuscrito A (thracae); cf. Knapp (1919a, 38).
} 
mente a épica e a lírica, ainda que não sejam tão evidentes, também têm seu lugar na palliata plautina, que, dessa forma, mais do que "metateatral", pode ser considerada, em sentido mais vasto, "metapoética", i.e. plena de referências à poesia.

Diferentemente do que ocorre com os termos tragoedia, tragoedus, tragicus, não é tão fácil encontrar, nas peças plautinas, termos latinos referentes aos gêneros épico ou lírico. No caso da épica, não são registrados, na tradição manuscrita latina anterior a Cícero e Horácio, os vocábulos epicus (Opt. Gen. 1; cf. ThLL v.2.664) e epos (Sat. 1.10.43; cf. ThLL v.2.697-8). Se houve registros de tais vocábulos antes dessa época, os textos se perderam.

Como já mencionamos em trabalho anterior, ${ }^{14}$ as peças plautinas não apresentam termos como lyricus ou melicus..$^{15}$ De início, os primeiros registros que nos chegaram são posteriores à época de Plauto: aparece lyricus em Horácio (Carm. 1.1.35; cf. ThLL vir.2.1951), e melicus, em Cícero (Opt. Gen. 1; cf. ThLL viıI.615-6). Ademais, não se pode perder de vista o fato de que "lírica" designa uma produção poética muito ampla, que abarca diversos "subgêneros", e já na Antiguidade não era um tipo de poesia de fácil delimitação. ${ }^{16}$

Apesar de tais dificuldades, é possível encontrar outras palavras-chave que marcam a presença dos referidos gêneros poéticos não dramáticos. No caso da lírica, por exemplo, há o termo elegeum (Merc. 409) na peça O mercador (Mercator) ${ }^{17}$ Trata-se da primeira aparição da palavra, designando "poema amoroso composto em dísticos elegíacos" (cf. OLD e ThLL v.2.339), de que se tem notícia:

\section{Quia illa forma matrem familias \\ Flagitium sit si sequatur, quando incedat per uias, \\ Contemplent, conspiciant omnes, nutent, nictent, sibilent, \\ Vellicent, uocent, molesti sint; occentent ostium; \\ Impleantur elegeorum meae fores carbonibus. \\ (Merc. 405-9)}

Porque com aquela aparência seria um escândalo se ela servisse de companhia a uma mãe de família: quando caminhasse pelas ruas, todos contemplariam, olhariam, ace-

14 "A poesia lírica na palliata plautina" (Costa 2012).

${ }^{15}$ Quanto ao termo carmen, o Oxford Latin dictionary (OLD, 3b) atesta um sentido específico de "poesia lírica", apontando registros a partir de Horácio (Ep. 2.2.59; 2.2.91). Porém, a vastidão de sentidos que o termo assume dentro de um mesmo campo semântico (a saber, o da música e da poesia), torna complexa a tarefa de precisar a partir de quando carmen passa a poder designar justamente "poesia lírica". O extenso verbete do ThLL, inclusive, traz à tona discussões sobre o uso do vocábulo.

${ }^{16} \mathrm{O}$ conceito de poesia lírica que preferimos adotar é amplo, e vai ao encontro do de E. Robbins (Fuhrer et Robbins 2011), para quem, em contexto grego, toda a produção poética do século vII a.C. até meados do século v a.C., com exceção da poesia em hexâmetro estíquico e do drama, deve ser considerada "lírica".

${ }^{17}$ Sobre a ocorrência, cf. também Bianco 2003. 
nariam com a cabeça, piscariam, assoviariam, beliscariam, chamariam, seriam inconvenientes; fariam serenatas à porta... minha porta ficaria coberta de pichações (lit. marcas de carvão) de versos elegíacos.

Nessa fala, Demifão (Demipho) comenta a comoção que provocaria a bela Pasicompsa (Pasicompsa) - a meretriz amante de seu filho, Carino (Charinus) - supostamente comprada para assistir a mãe. O receio era de que, quando a moça saísse às ruas, os homens, levados por sua beleza, chegariam a escrever versinhos elegíacos na porta da casa, i.e. versos amorosos. Tem-se aqui, então, a menção direta a um dos tipos de poesia classificados em alguns cânones antigos ${ }^{18}$ e modernamente sob a nomenclatura de "lírica". ${ }^{19}$

Quanto à épica, como já afirmamos, ao contrário do que ocorre com a tragédia, não há menção direta ao gênero. Tampouco ocorre referência a um "subgênero", como observamos no caso da lírica. Mas veja-se o seguinte trecho da peça Truculento (Truculentus):

Ne expectetis, spectatores, meas pugnas dum praedicem:

Manibus duella praedicare soleo, haud in sermonibus.

Scio ego multos memorauisse milites mendacium:

Et Homeronidam et postilla mille memorari potis,

Qui et conuicti et condemnati falsis de pugnis sient.

(Truc. 482-6)

Não esperem, espectadores, até que eu proclame minhas batalhas: é com as mãos que eu costumo proclamar meus combates, não com conversa. Bem sei eu que muitos soldados relembram mentiras: pode-se relembrar o Homerônidas, e outros mil depois dele, que foram declarados culpados e condenados por causa de falsas batalhas.

Na passagem acima, o soldado Estratófanes (Stratophanes), está se referindo a combates - algo que, segundo o prólogo de Os cativos, seria um tópos da tragédia. Não se pode negar, porém, que guerras e conflitos da mesma ordem são frequentes também na poesia épica. O trecho supracitado da comédia Truculento parece mesmo sugerir isso: a personagem exemplifica quem fica "relembrando falsas batalhas" ${ }^{20}$ citando um certo Homeronidam (Truc. 485), cujo nome (que traduzimos por "Homerônidas") alude quer a toda

\footnotetext{
${ }^{18}$ Sobre os cânones líricos da Antiguidade greco-romana, cf., por ex., Fuhrer et Robbins 2011.

${ }_{19}$ Outra presença marcante da lírica na obra plautina está em O soldado fanfarrão (Miles gloriosus), peça em que ocorre uma alusão ao fragmento 31 de Safo (Mil. 1246-7, 1260-2, 12704). Tratamos do tema no artigo "A poesia lírica na palliata plautina" (Costa 2012) supracitado. Sobre as influências que Plauto teria exercido sobre os poetas líricos que surgiriam em Roma, especialmente no tocante ao vocabulário amoroso, cf. Bellido 1989, Martin 1905, Roussel 2009, Yardley 1987. Sobre mesclas de gêneros poéticos em Ovídio, cf. ainda Bem 2011.

${ }^{20}$ Para discussão sobre a relação entre épica e mentira em Plauto, cf. Cardoso 2005, 238; Costa 2010b, 32-3.
} 
uma categoria de rapsodos que narravam feitos heroicos nos moldes dos expostos nos poemas homéricos, ${ }^{21}$ quer, indiretamente, ao ilustre Homero.

Ainda que não deixe de garantir a presença da épica na obra de Plauto, essa referência ao epos grego em Truculento não é uma menção ao gênero tão explícita quanto os exemplos que anteriormente comentamos. Nem tampouco tão claramente desenvolvida quanto a seguinte alusão a um tragediógrafo antigo, extraída da comédia O cabo (Rudens):

Pro di immortales! Tempestatem cuiusmodi

Neptunus nobis nocte hac misit proxima!

Detexit uentus uillam. Quid uerbis opust?

Non uentus fuit, uerum Alcumena Euripidi,

Ita omnis de tecto deturbauit tegulas,

Inlustriores fecit fenestrasque indidit.

(Rud. 83-8)

Pelos deuses imortais! Que tempestade Netuno nos enviou noite passada! O vento levou o teto de nossa casa de campo! Que necessidade há de ficar falando? Na verdade não foi vento, mas uma Alcmena de Eurípides, de tal forma arrancou todas as telhas do telhado, abriu ali janelas e fez com que dali entrasse mais luz.

A menção ao notável trágico grego é indiscutivelmente mais direta, e, portanto, inferimos que deveria ser mais acessível ao público. Certamente, à época de Plauto, ambas seriam inteligíveis para quem tivesse algum conhecimento do cânone poético da Antiguidade Clássica. Mas o efeito da citação é diverso em um e outro caso: a passagem em $O$ cabo remete a um autor, uma obra e um gênero específicos, ao passo que aquela de Truculento alude a um contexto mais amplo.

Dessa forma, então, parece difícil negar que, em termos de menção direta, a tragédia triunfa sobre a épica e a lírica nas obras de Plauto: as alusões aos gêneros não dramáticos são não apenas em menor número, mas também menos evidentes. Lembremo-nos, porém, que não só por referências nominais ou terminológicas é possível identificar a presença de outros gêneros nas comédias plautinas: o emprego de determinados topoi poéticos também pode contribuir, ainda que de modo menos imediato, para a identificação de gêneros e mesclas de gêneros.

Um tópos partilhado pela tragédia e pela épica é o já comentado acima: o da guerra. Retomando o argumento exposto no prólogo de Os cativos (Capt. 58-62), esse não deveria ser um tema explorado na palliata romana

\footnotetext{
${ }^{21}$ Cf. por exemplo, o termo homerista, que o OLD define como "um declamador de Homero, rapsodo" ("a reciter of Homer, rhapsode"). Em língua latina, o termo latino Homeronida não é registrado em outro lugar.
} 
(assim como não o teria sido na Comédia Nova grega). No entanto, há várias passagens significativas na obra plautina relacionadas à guerra, dentre elas, destaquemos: o discurso de batalha do escravo Sósia (Sosia), em Anfitrião (Amph. 186-247, 250-62), e a monodia do escravo Crísalo (Chrysalus), em Báquides (Bacch. 925-77). ${ }^{22}$

A longa narrativa de Sósia conta como os tebanos, liderados pelo general Anfitrião, venceram os teléboas em campo de batalha. $\mathrm{O}$ tom épico-trágico do trecho é facilmente perceptível; mas a tentativa de estabelecer até que ponto o discurso é mais característico de uma epopeia ou de uma tragédia exige uma observação mais atenta. ${ }^{23}$ Segundo a argumentação de R. Oniga, que publicou um detalhado estudo sobre a passagem, ${ }^{24}$ há elementos ali que apontariam predominantemente para a épica.

De início, Oniga $(1985,205)$ estabelece uma relação entre os relatos de um cantor épico e o discurso de Sósia no que diz respeito à fonte de conhecimento acerca dos feitos narrados: em ambos os casos a perspectiva do narrador seria onisciente. Essa onisciência, porém, não é exatamente da mesma natureza para um e outro; há, conforme aponta o estudioso, diferenças a se levar em consideração. Sósia não viu o que se passou durante a batalha porque preferiu ficar escondido em uma tenda bebendo vinho (Amph. 199, 425-6, 431), e então, mentiroso (Amph. 198), ele alegadamente compõe sua narrativa com base no que ouviu falar (Amph. 200). O poeta épico, por sua vez, seria onisciente por concessão das musas; assim, não precisaria ter presenciado os feitos para narrá-los com propriedade. Em suma: o épico recria sua narrativa a partir de uma tradição, o escravo Sósia inventa a sua em torno de testemunhos alheios.

No entanto, segundo Oniga, ainda que haja essa disparidade quanto à "inspiração", ambos se assemelham mais um ao outro que a uma personagem de tragédia com função relatora similar, o mensageiro. O mensageiro trágico, de acordo com Oniga, conta o que viu com seus próprios olhos apenas, ${ }^{25}$ o que de maneira alguma condiz com o que fez Sósia. Quanto a esse ponto, então, essa passagem da peça Anfitrião em que Sósia ensaia seu relato a Alcmena seria mais caracterizada pela épica do que pela tragédia.

Por um lado, Oniga destaca, além desse critério, ainda outros aspectos que aproximariam a narrativa de batalha de Sósia de um épico, como a pre-

\footnotetext{
22 Sobre o tema da guerra em Plauto, cf. Costa 2010a.

${ }^{23}$ Para considerações mais detalhadas sobre a o caráter trágico e/ou épico do discurso de batalha de Sósia, cf. Costa 2010b, 31-8.

${ }^{24}$ Oniga 1985.

${ }_{25}$ "Contrariamente alla prospettiva onnisciente e distaccata del cantore epico (concessagli dall'onniscienza divina delle Muse), la narrazione tragica è sempre focalizzata su ciò che il nunzio ha visto personalmente, partecipando in modo umano e appassionato aglì eventi" (Oniga 1985, 123).
} 
sença de arcaísmos $(1985,180)$ e a possibilidade de o início do relato (Amph. 186-96) ser uma paródia de proêmio temático $(1985,173)$. Por outro lado, o estudioso não deixa de afirmar que os arcaísmos também são característicos da tragédia, ${ }^{26}$ e assume que a parte inicial da narrativa do escravo pode ser também entendida, segundo o modelo trágico, como a antecipatio com que os mensageiros desse tipo de drama costumam iniciar seu discurso.

Essa complexidade que se encontra na peça Anfitrião ilustra a dificuldade de se precisar se elementos épico-trágicos nas comédias plautinas seriam mais característicos de um ou de outro gênero. Nossas pesquisas sobre esse aspecto tem nos levado a concordar com estudiosos como D. M. Christenson ${ }^{27}$ quanto à seguinte hipótese: talvez a épica que se possa entrever na narrativa de Sósia seja, afinal, uma épica expressa via tragédia.

Parece sustentar essa conjectura uma consideração do próprio Oniga a respeito das falas de mensageiros nas tragédias: "Il nunzio tragico indulge infatti spesso a una stilizzazione epica del proprio racconto, nel senso di una narrazione oggettiva, caratterizzata dall'occasionale recupero di singole tematiche o locuzioni omeriche" $(1985,123)$. Ou seja, ao ver a encenação de Sósia, o público plautino se lembraria não diretamente da épica, e sim de uma tragédia que encenasse tais momentos épicos. Esse pressuposto parece funcionar bem para o caso da tragicocomoedia Anfitrião, mas e quanto a Báquides?

A monodia de Crísalo também aborda episódios míticos, mas, desta vez, trata-se do ciclo troiano: em uma extensa Glorifizierung, o escravo compara personagens e acontecimentos da peça aos feitos e heróis da guerra de Troia. Parece natural e quase imediata a associação da queda da afamada cidadela (bem como eventos anteriores e posteriores) a poemas épicos. Logo, um primeiro contato com essa passagem da peça Báquides, pode sugerir que haja, ali, especialmente a presença do gênero épico em Plauto.

Há que se considerar, porém, os argumentos levantados por H. D. Jocelyn, autor de um minucioso estudo sobre o trecho em questão (com foco especialmente na polêmica a respeito de quais versos ali seriam provavelmente plautinos e quais seriam fruto de interpolação). ${ }^{28}$ Jocelyn (1969, 138 n.21) lembra que grande parte dos temas conhecidos das primeiras produções trágicas de Roma está relacionada ao ciclo troiano. ${ }^{29}$ Ao comentar o

${ }_{26}$ “(...) gli arcaismi sono infatti un elemento fondamentale dello stile tragico e ancor più di quello epico" (Oniga 1985, 180).

${ }^{27}$ Plautus 2000.

${ }^{28}$ Jocelyn 1969.

${ }^{29}$ Por exemplo, Achilles, Aegisthus, Aiax mastigophoros, de Lívio Andronico (c. 280-c. 200 a.C.); Achilles, Aiax, Andromacha, Hectoris lytra, Hecuba, de Ênio (c. 239-169 a.C.); Achilles, Aegisthus, Agamemnonidae, Astyanax, Clutemestra, Hecuba, Hellenes, Myrmidones, Neoptolemus, Philocteta, Troades, de Ácio (170-84 a.C.); cf. Albrecht 1997, 113, 130-1, 155-6. 
quão elípticas são as alusões às lendas heroicas na obra de Plauto, o estudioso postula que o público plautino deveria ter um alto grau de conhecimento sobre o assunto, provavelmente por conta da representação de tragédias como Equos troianus ${ }^{30}$ (1969, 137-8).

Talvez corrobore para que se considere a influência da tragédia na composição do trecho o fato de que um dos versos mais comentados da monodia de Crísalo ("O Troia, o patria, o Pergamum; o Priame, periisti senex", Bacch. 933), é célebre justamente pelos paralelos que se podem estabelecer entre ele e outras tragédias conhecidas, como a Medeia de Eurípides (Med. 166). ${ }^{31}$

Percebe-se, então, com base nos exemplos discutidos de Anfitrião e Báquides, que, mesmo quando o tema parece apontar para a épica, uma análise mais cuidadosa revela que a tragédia (pelo modo como o tema é enunciado, representado) prevalece, segundo o entender dos estudiosos em geral. Mas se, em Plauto, a tragédia sobrepuja o gênero épico e o lírico, qual seria a relação daquela com a comédia? Para responder a essa questão, convém retomar os trechos de peças plautinas em que ocorrem as menções mais diretas ao gênero trágico. Para ilustrar tal procedimento, iniciemos com Anfitrião:

Nam quid ego memorem, ut alios in tragoediis

Vidi, Neptunum, Virtutem, Victoriam,

Martem, Bellonam, commemorare quae bona

Vobis fecissent, quis benefactis meus pater,

Deorum regnator, architectust omnibus?

(Amph. 41-5)

Vi outros - Netuno, Virtude, Vitória, Marte, Belona - em tragédias a recordar as benfeitorias que fizeram para vocês; mas por que eu haveria de recordar assim as benfeitorias de meu pai, o soberano dos deuses, que é o arquiteto de todas as coisas?

Logo na primeira ocorrência do termo, antes mesmo de o prologuista, Mercúrio, dar início à discussão sobre o gênero da peça, já se encontra um julgamento negativo sobre a tragédia. Christenson lembra (2000, 144) que a crítica e a ridicularização explícitas da tragédia, apesar de não serem temas encontrados em Menandro, ${ }^{32}$ foram bastante comuns na Comédia Antiga

\footnotetext{
${ }^{30}$ Uma peça com tal título é atribuída tanto a Lívio Andronico (Nônio 475.10) quanto a Névio (Macróbio, Sat. 6.1.38); cf. Jocelyn (1969, 138 n.21) e Albrecht (1997, 113, 120).

${ }^{31}$ Outros paralelos podem ser estabelecidos: As fenícias, também de Eurípides (Phoen. 611-3); Andrômaca (Andromacha), de Ênio ("O pater, o patria, o Priami domus", Andr. 92); Eneida (Aeneis), de Virgílio ("O patria, o diuom domus Ilium et incluta bello / moenia Dardanidum", Aen. 2.241-2).

${ }^{32}$ Isso não significa, contudo, que a tragédia não se faça presente na obra de Menandro. Na peça Epitrepontes, por exemplo, o comediógrafo grego remete, por meio das palavras do escravo Onesimos, à tragédia Auge, de Eurípides (em ambos os dramas, uma jovem é estuprada em um festival noturno e dá a luz uma criança, que é posteriormente reconhecida por carregar um anel do pai). Sobre as semelhanças entre essas duas peças (e para demais aproximações entre as obras
} 
grega e que, de acordo com alguns estudiosos, parecem ter perdurado também na Comédia Média e na Nova. ${ }^{33}$

Em Anfitrião, pouco antes de alegar que a presente peça seria também uma tragédia, Mercúrio rechaça o discurso que outras personagens divinas teriam no referido gênero. Nas próximas referências, Mercúrio alega que o desagrado em relação à tragédia se verificaria também na reação dos espectadores:

Nunc quam rem oratum huc ueni, primum proloquar;

Post argumentum huius eloquar tragoediae.

Quid contraxistis frontem? Quia tragoediam

Dixi futuram hanc? Deus sum, commutauero.

Eandem hanc, si uultis, faciam | ex tragoedia

Comoedia ut sit omnibus isdem uorsibus

Vtrum sit an non uoltis? Sed ego stultior,

Quasi nesciam uos uelle, qui diuus siem.

Teneo quid animi uostri super hac re siet.

(Amph.50-5)

Agora, exporei primeiro o que vim aqui pedir; depois, contarei o argumento desta tragédia. Por que vocês franziram a testa? Porque eu disse que será uma tragédia? Sou um deus, vou mudar! Essa mesma, se quiserem, farei com que de tragédia seja comédia, com todos os mesmos versos. Vocês querem que seja assim ou não? Mas eu sou um bobo, como se não soubesse o que vocês querem, sendo eu um deus. Sei qual é o pensamento de vocês acerca desse assunto.

Nessa passagem, Mercúrio antecipa a reação contrariada que a plateia teria, e "adivinha" sua preferência pela comédia, ${ }^{34}$ ao passo que, na peça Os cativos, o Prólogo anuncia aos espectadores que eles não precisariam recear ("ne uereamini", Capt. 58) que se apresentassem batalhas no palco, algo mais apropriado para um espetáculo trágico:

Ne uereamini,

Quia bellum Aetolis <esse> dixi cum Aleis.

Foris illic extra scaenam fient proelia.

Nam hoc paene iniquomst, comico choragio

Conari desubito agere nos tragoediam.

de Menandro e Eurípides), ver Anderson 1982; Andrewes 1924, 5; Gutzwiller 2000, 113; Katsouris 1975; Slater 1988, 259 n. 35.

${ }^{33}$ Ocorrem também, na obra plautina, críticas a comédias, como em $O$ mercador. Na peça, a personagem Carino afirma, em seu monólogo de abertura: "Non ego item facio ut alios in comoediis" ("Eu não faço do mesmo modo que outros em comédias", Mer. 3). As referências à comédia - muito mais numerosas que as alusões a outros gêneros (cf. Knapp 1919a, 36 ss.) - não fazem parte do escopo do presente trabalho.

${ }^{34}$ Pode-se encontrar, em Aristófanes (Av. 785-9), um exemplo do tratamento convencional da tragédia como fonte de angústia ou tédio. 
Proin si quis pugnam expectat, litis contrahat;

Valentiorem nactus aduersarium

Si erit, ego faciam ut pugnam inspectet non bonam,

Adeo ut spectare postea omnis oderit.

(Capt. 58-66)

Não fiquem receosos por eu ter falado <haver> uma guerra entre os etólios e os eleus: lá fora, para além do palco é que vão acontecer os combates. Pois chega a ser quase injusto isto: tentarmos, de repente, com uma companhia cômica, apresentar uma tragédia. Por esse motivo, se alguém aí espera uma batalha, que arranje umas brigas! Se houver algum adversário mais forte, eu farei com que observe uma batalha nada boa e, a partir daí, passará a odiar assistir a qualquer uma.

Nessa passagem, batalhas trágicas (proelia, Capt. 6o) são comparadas a "brigas que se arranjam por aí" (litis, Capt. 63), ${ }^{35}$ rebaixando, de certa forma, o tópos bélico. Ademais, sugere-se que quem já esteve em um combate ruim não gostaria sequer de ver qualquer outro, encontrando um eventual desprazer ao assistir a espetáculos que os representassem (Capt. 64-6). Infere-se que a comédia a ser representada, por outro lado, sem combates em cena, deveria ser mais aprazível.

Segundo propomos, os últimos exemplos analisados mostram mais claramente passagens que representam relações de poder entre gêneros na obra plautina. Nas peças aqui brevemente referidas, apesar de a tragédia marcar presença de forma mais enfática que o fazem a épica e a lírica, ela não triunfa sobre a comédia.

Isso porque, segundo o que pretendemos ter indicado, em contextos de emulação entre o gênero cômico e o trágico, é o primeiro que, rebaixando o segundo, declaradamente sai vitorioso em termos de efeito (riso cômico e deleite) junto ao público. Mais especificamente, a suposição é de que, em Plauto, havendo embate entre gêneros, a tendência ao triunfo é da comédia.

Essa hipótese precisa ser averiguada ao se levar em consideração não apenas as alusões a gêneros outros na palliata de Plauto, mas também as referências à própria comédia, o que tencionamos fazer no prosseguimento dos estudos sobre o tema específico. Contudo, é possível constatar, até o presente momento de nossas pesquisas, que as menções a gêneros, quaisquer que sejam, geram enriquecedores efeitos na apreciação da obra plautina, evidenciando o poder da metapoesia dentre os recursos poéticos de que Plauto se valia para compor seu teatro.

\footnotetext{
${ }^{35} \mathrm{O}$ termo lis parece se referir a disputas e desavenças (por vezes em caráter de ação judicial) menores, que não chegam à proporção de uma guerra, cf. OLD.
} 


\section{REFERÊNCIAS}

Abel, K. 1955. Die Plautusprologue. Frankfurt am Main.

Abel, L. 1963. Metatheatre: A new view of dramatic form. New York: Hill and Wang.

Albrecht, M. 1997. A history of Roman literature. Leiden: Brill.

Anderson, W. S. 1982. "Euripides' Auge and Menander's Epitrepontes." Greek, Roman, and Byzantine Studies 23(2):167-77.

Andrewes, M. 1924. "Euripides and Menander." The Classical Quarterly 18(1):1-10.

Aristófanes. 2005. Duas comédias: Lisístrata e As tesmoforiantes. Tradução, apresentação e notas de Adriane S. Duarte. São Paulo: Martins Fontes.

Barchiesi, M. 1969. "Plauto e il 'metateatro' antico." Il Verri 31:113-30.

Bayerische Akademie der Wissenschften, ed. 1900-1999. Thesaurus linguae latinae. Leipzig: Teubner.

Bellido, J. A. 1989. "El motivo literario de la militia amoris en Plauto y su influencia en Ovidio." Estudios Clásicos 31(95):21-32.

Bem, L. A. 2011. Metapoesia e confluência genérica nos Amores de Ovídio. Tese de doutorado. Universidade de Campinas.

Bianco, M. M. 2003. “Nota a Plauto, Merc. 409." Pan 21:101-4.

Cardoso, I. T. 2005. Ars plautina. Tese de doutorado. Universidade de São Paulo.

Cardoso, I. T. 2010. "Ilusão e engano no teatro de Plauto." In Estudos sobre o teatro antigo, organizado por Zélia A. Cardoso e Adriane S. Duarte, 95-126. São Paulo: Alameda.

Costa, L. N. 2010a. "Bellum plautinum: a guerra no palco da palliata." Anais do Seta 5:550-9.

Costa, L. N. 2010b. Mesclas genéricas na "tragicomédia" Anfitrião de Plauto. Dissertação de mestrado. Universidade de Campinas.

Costa, L. N. 2012. "A poesia lírica na palliata plautina." Anais do Seta 6:235-49.

Ennius. 1967. The tragedies of Ennius: The fragments. Edited with an introduction and commentary by H. D. Jocelyn. Cambridge: Cambridge University Press.

Fuhrer, T.; Robbins, E. 2011. "Lyric poetry." In Brill's New Pauly. Antiquity volumes edited by Hubert Cancik and Helmuth Schneider. Brill.

Glare, P. G. W., ed. 1982. Oxford Latin Dictionary. Oxford: Clarendon Press.

Gutzwiller, K. 2000. "The tragic mask of comedy: metatheatricality in Menander." Classical Antiquity 19(1):102-37.

Katsouris, A. G. 1975. Tragic patterns in Menander. Athens: Hellenic Society for Humanistic Studies.

Knapp, C. 1919a. "References in Plautus and Terence to plays, players and playwrights." Classical Philology 14(1):35-55.

Knapp, C. 1919b. "References to literature in Plautus and Terence." The American Journal of Philology 40(3):231-61.

Kroll, W. 1924. "Die Kreuzung der Gattungen." In Studien zum Verständnis der römischen Literatur, 202-24. Stuttgart: J. B. Metzler.

Jocelyn, H. D. 1969. "Chrysalus and the fall of Troy." Harvard Studies in Classical Philology 73:135-52.

Leigh, M. 2004. Comedy and the rise of Rome. Oxford: Oxford University Press. 
Lodge, G. 1962. Lexicon Plautinum. Hildesheim: Greg Olms Verlagsbuchhandlung.

Martin, J. 1905. "Zur Entstehung der römischen Elegie." Rheinisches Museum für Philologie 60:38-105.

Oniga, R. 1985. "Il canticum di Sosia: forme stilistiche e modelli culturali." Materiali e Discussioni 14:113-208.

Perseus Digital Library. <http:// www.perseus.tufts.edu/>. Acesso em 20/09/2015.

Plaute. 1970. Comédies: Mostellaria, Persa, Poenulus. Tome V. Texte établi et traduit par Alfred Ernout. Paris: Les Belles Lettres.

Plaute. 1972a. Comédies: Cistellaria, Curculio, Epidicus. Tome III. Texte établi et traduit par Alfred Ernout. Paris: Les Belles Lettres.

Plaute. 1972b. Comédies: Pseudolus, Rudens, Stichus. Tome VI. Texte établi et traduit par Alfred Ernout. Paris: Les Belles Lettres.

Plaute. 1992. Comédies: Menaechmi, Mercator, Miles gloriosus. Tome IV. Texte établi et traduit par Alfred Ernout. Paris: Les Belles Lettres.

Plaute. 1996. Comédies: Bacchides, Captiui, Casina. Tome II. Texte établi et traduit par Alfred Ernout. Paris: Les Belles Lettres.

Plaute. 2001a. Comédies: Trinummus, Truculentus, Vidularia. Tome VII. Texte établi et traduit par Alfred Ernout. Paris: Les Belles Lettres.

Plaute. 2001b. Comédies: Amphitryon, Asinaria, Aulularia. Tome I. Texte établi et traduit par Alfred Ernout. Paris: Les Belles Lettres.

Plautus. 2000. Amphitruo. Edited by D. M. Christenson. Cambridge: Cambridge University Press.

Plautus. 1896. Comoediae: Miles gloriosus, Mostellaria, Persa, Poenulus, Pseudolus, Rudens, Stichus, Trinummus, Truculentus, Vidularia, Fragmenta. Recensuit et emendauit Fridericus Leo. Berolini: Weidmann.

Plautus. 1921. Comoediae: Miles gloriosus, Mostellaria, Persa, Poenulus, Pseudolus, Rudens, Stichus, Trinummus, Truculentus, Vidularia, Fragmenta. Recognouit breuique adnotatione critica instruxit W. M. Lindsay. Oxonii: e Typographeo Clarendoniano.

Roussel, D. 2009. "Le triangle amoureux au banquet: réécriture élégiaque d'un motif comique." In La théâtralité de l'œuvre ovidienne, éditée par I. Jouter, 205-24. Nancy: Association pour la diffusion de la recherche sur l'antiquité.

Slater, N. W. 1985. Plautus in performance: The theatre of the mind. Princeton: Princeton University Press.

Slater, N. W. 1988. "The fictions of patriarchy in Terence's Hecyra." The Classical World 81(4):249-60.

Traill, A. 2005. "Acroteleutium's Sapphic infatuation (Miles 1212-83)." The Classical Quarterly 55(2):518-33.

Virgile. 1981. Énéide: Liores I-IV. Tome I. Texte établi et traduit par Jacques Perret. Paris: Les Belles Lettres.

Yardley, J. C. 1987. "Propertius 4.5, Ovid Amores 1.6 and Roman comedy." Proceedings of the Cambridge Philological Society 33:179-89.

Zagagi, N. 1980. Tradition and originality in Plautus: Studies of the amatory motifs in Plautine comedy. Göttingen: Vandenhoeck \& Ruprecht.

Zagagi, N. 1986. "Mythological hyperboles and Plautus." The Classical Quarterly 36(1):267. 


\section{$*$}

Title. Plautus and the triumph of tragedy

Abstract. The presence of various tragic, epic and even lyric elements in the comedy of Titus Maccius Plautus (c. 254-184 a.C.) has been recognized by scholars like Christenson (2000), Oniga (1985) and Traill (2005), respectively. However, such miscellany of poetic genres in the Plautine corpus doesn't depict them in a peaceful coexistence. On the contrary: many times the evocation of other poetic genres seems to suggest an atmosphere of emulation between those genres and the comic one. Our researches have been pointing to the preponderance of allusions to tragedy (or intermediated by it). As we would like to stress though, it is not a mere matter of amount of references: sometimes the dispute (and the tradicional hierarchy) is even thematized, as in Amphitruo, The captives, Truculentus. In this paper we sought to observe more closely, in certain Plautine passages, the supposed triumph that the tragedy would have over the comedy, in order to determine to what extent this is verifiable in some of the poet's plays.

Keywords. Plautus; comedy; tragedy; epic; lyric. 